La estructura morfológica y el contenido semántico de los topónimos de la provincia de Huarochirí (Perú)

\title{
LA ESTRUCTURA MORFOLÓGICA Y EL CONTENIDO SEMÁNTICO DE LOS TOPÓNIMOS DE LA PROVINCIA DE HUAROCHIRÍ (PERÚ) ${ }^{1}$
}

\author{
Dina Emeteria Chávez-Bellido \\ Universidad Ricardo Palma (Perú) \\ dina.chavez@urp.edu.pe \\ Margot Luliana Berrío-Quispe \\ Universidad Ricardo Palma (Perú) \\ margoth.berrio@urp.edu.pe \\ Luis Miguel Cangalaya-Sevillano \\ Universidad Peruana de Ciencias Aplicadas (Perú) \\ luis.cangalaya@upc.edu.pe \\ Dennis Arias-Chávez \\ Universidad Continental (Perú) \\ darias@continental.edu.pe
}

Recibido: 12/08/2020 - Aprobado: 16/11/2020 - Publicado: 15/04/2021

DOI: doi.org/10.17533/udea.lyl.n79a11

\begin{abstract}
Resumen: Este estudio cualitativo analiza 140 topónimos de la provincia peruana de Huarochirí, departamento de Lima, bajo los aspectos morfológico y semántico. El estudio de los topónimos presentó características relevantes, como lexías simples y compuestas, que superan en número a lexemas simples, y determinó diferentes estados de simbiosis cultural, donde se destaca la capacidad onomasiológica de los antiguos pobladores para los topónimos con su cosmovisión. Se concluye que lenguas como el jacaru, el aimara y el quechua, que se hablaron antes que el español en la zona peruana de Huarochirí, dejaron en los topónimos una clara huella de su presencia.

Palabras clave: morfología; semántica; topónimos; Huarochirí.

\section{MORPHOLOGICAL STRUCTURE AND SEMANTIC CONTENT OF THE TOPONYMS OF HUAROCHIRÍ PROVINCE (PERU)}

\begin{abstract}
This qualitative study analyzes 140 place names or toponyms of the Peruvian province of Huarochirí, department of Lima, under two aspects: morphological and semantic. The study of the toponyms presented relevant characteristics, such as simple and compound lexies, which outnumber simple lexemes; and determined different states of cultural symbiosis, in which it highlights the onomasiological ability of the ancient settlers to associate place names with their cultural worldview. It concludes that languages such as Jacaru, Aymara and Quechua, that were spoken before Spanish in the Peruvian area of Huarochirí, left in the place names a clear imprint.
\end{abstract}

Key words: morphology; semantics; toponyms; Huarochirí.

1. El presente estudio es una extensión de la investigación titulada Estudio morfológico y semántico de los topónimos de la Provincia de Huarochirí (2019), dirigida por la Mg. Dina Chávez (2019) en la Escuela de Postgrado de la Universidad Nacional de Educación «Enrique Guzmán y Valle».

Editores 
La estructura morfológica y el contenido semántico de los topónimos de la provincia de Huarochirí (Perú)

\section{Introducción}

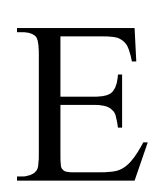

$\mathrm{n}$ el presente trabajo se analiza un conjunto de topónimos en sus aspectos morfológicos y semánticos de la provincia de Huarochirí, provincia del departamento de Lima, con registros de sus tradiciones y nombres desde la época de la colonia, como se patentiza en el Manuscrito de Huarochirí (Runa Yndio Niscap), realizado por el padre Francisco de Ávila en 1608. Se tiene en cuenta que, a la fecha, en la zona no se habla ninguna lengua nativa, por lo que es importante conocer los significados de los topónimos y el grado en que las personas del lugar los entienden.

Los topónimos, que son nombres propios de un lugar, son archivos vivientes que expresan la cultura e historia de un pueblo. Su estudio sirve de herramienta auxiliar para explicar la historia de los lugares (Rodríguez, Rodríguez \& Vázquez, 2017; Frago, 1991) por las huellas lingüísticas que estas dejan, las cuales suelen corresponder a una o varias lenguas que coexistieron en el territorio (Cuba, 2018). El estudio de los topónimos de Huarochirí se realiza por la necesidad de conocer cuáles lenguas originarias tales como el jacaru, el aimara, el quechua u otras han quedado fijadas como sustratos en nombres de lugares, personas, animales, plantas y en el entorno ecológico de esta provincia del departamento de Lima.

La toponimia investiga los nombres con que han sido designados espacios geográficos por las agrupaciones humanas que habitaron esos lugares desde tiempos lejanos (Solís, 1997; Chávez, 2003). El topónimo en sí es el nombre que determina cualquier punto geofísico. En esa línea, Trapero y Santana (2016), Mollo y Vera (2017), Sudario et al. (2014), Cerrón-Palomino (2015b) y Baldoceda (1993) han señalado que los lugareños son las personas que mejor conocen el significado de los topónimos, ya que están utilizándolos continuamente en su vida diaria. Por eso, ellos son las primeras fuentes para el investigador.

El estudio de los topónimos intenta descubrir el pensamiento filosófico de las generaciones pasadas que poblaron aquella región y desentrañar qué ideas de ellas permanecen en la cultura actual de los pueblos. Asimismo, busca reconocer cuáles de los sustratos fonético y morfológico se revelan y se encuentran en la lengua que hablan esas comunidades. Lo anterior sustenta la importancia de los estudios de carácter toponímico, sobre todo por sus implicaciones sociales, culturales, políticas, etnográficas, filológicas y lingüísticas (Cerrón-Palomino, 2015b). Por todo esto, el objetivo de la investigación es examinar las características morfológicas y semánticas de los topónimos de la provincia de Huarochirí, con lo cual se pretende describir la clasificación según su filiación lingüística y explicar los elementos motivadores en la denominación de los mismos.

\section{Estado de la cuestión}

El estudio de los topónimos tiene respaldo vital en los trabajos de gramática de la lengua quechua que datan del siglo XVI. Entre ellos destacan los estudios de Gonçález (1580/1989) y Santo Tomás (1570/1995), quienes abordan los aspectos fonético-fonológico, morfológico y semántico de esta lengua. A estos se suma el estudio 
La estructura morfológica y el contenido semántico de los topónimos de la provincia de Huarochirí (Perú) semántico, diacrónico y sincrónico del quechua, aimara y mochica realizado por Durand (1921). Ahora bien, en lo que respecta a estudios recientes sobre la toponimia, se destaca el realizado por Baldoceda (1993), en el que se develan valiosos vestigios idiomáticos de la provincia de Canta — departamento de Lima-, que guardan parecidos con los de Huarochirí, pues ambas etnias pertenecían a la misma división geográfica prehispánica de Hurin y Hanan Yauyos. En lo que respecta al dialecto Junín Huanca, sobresalen las investigaciones de CerrónPalomino y Chacón (1976), en cuyos trabajos de gramática y lexicón se esclarece que el dialecto de esta zona pertenece al Quechua I, que en el tiempo de estudio contaba con 300 mil hablantes.

Además, en estos estudios se advierte que en ese dialecto se utiliza el fonema lateral, alveolar sonoro /1/ en lugar de la vibrante /r/. Por ejemplo, en el habla quechua cercana a Junín se dice runtu al huevo, pero en el dialecto juninense se dice luntu. También hay palabras con la terminación nominal -sh, que en otros lugares presentan la forma $-s h a$ - también $-s$ o -sa-, que se añade a sustantivos o adjetivos para indicar matiz o para dar forma a la palabra. En el quechua de Áncash, por su parte, existe el adjetivo qarwa, «verde amarillento», y qarwash, que es «amarillo» (Parker \& Chávez, 1976); en jacaru, wich'u es «delgado» y wich 'usa «delgadísimo» (Belleza, 1995); mientras que, en quechua, se observa la muy común palabra añas, «zorrino», donde la raíz es aña, en comparación con el aimara añathuya, «zorrino».

En cuanto al estudio de los topónimos de otras provincias, figura el realizado en el departamento de Áncash, lugar en el que se han desarrollado diversas investigaciones. Una de ellas es la de Parker (1975), quien señala que las voces quechuas de esa zona difieren de las otras hablas quechuas del Perú. También precisa que existe una diferencia entre la variante del Callejón de Huaylas y la del Callejón de Conchucos, ambas del departamento de Ancash, Perú. En la necesidad de facilitar la toma de contacto con las lenguas originarias, el autor sugirió que los topónimos deben tener una ortografía propia, dependiendo de la lengua a la que pertenezcan. Sustentó, además, que el estudio de los topónimos es un aporte etnográfico y etnosemántico, que requiere de un trabajo multidisciplinario para desentrañar el significado de los sustratos lingüísticos de culturas más antiguas que poblaron la zona de estudio. Por su parte, Chávez (2003), Mejía (2007), Solís (1997) y Amaro et al. (2014) resaltaron la necesidad de ubicar los topónimos en el mapa de los distritos del país. A ello se suma el estudio de Cusihuamán (1973) sobre la variante quechua Cuzco-Collao, similar a la que también se habla en Bolivia, aunque con algunas diferencias. Este autor cusqueño marcó las diferencias de esta variedad con respecto a los dialectos existentes en el área andina peruana.

De acuerdo con Trapero y Santana (2016) y Mollo y Vera (2017), los topónimos vienen sugeridos y motivados por el contexto geográfico y ambiental. El calibre de su trabajo ha logrado que se corrijan los topónimos en los mapas cartográficos argentinos oficiales y también que se coloquen en las carreteras de la Argentina. En ese sentido, los estudios de Trapero y Santana (2016) también ayudaron a revitalizar la lengua nativa guanche de Las Islas Canarias; en tanto que los aportes de Mollo y Vera (2017) y Fernández $(2002,2001)$ se enfocaron en el mapuche y ranquel.

En cuanto al estudio del jacaru - lengua de la familia aimara hablada en el distrito de Tupe, Provincia de 
La estructura morfológica y el contenido semántico de los topónimos de la provincia de Huarochirí (Perú) Yauyos, Departamento de Lima_- es relevante mencionar el trabajo de Hardman (1973) en torno a tres aspectos: el fonológico, el morfológico y el sintáctico. Sus aportes impactaron en la recuperación de esa lengua originaria y llevaron a que, desde el Ministerio de Educación del Perú, se implementara la educación bilingüe jacarucastellano en esa zona. A ello se suma un estudio exhaustivo del jacaru realizado por Belleza (1995), quien en su Vocabulario jacaru-castellano/ castellano-jaqaru rescata casi la totalidad de los sufijos de dicha lengua.

Si bien estas investigaciones y trabajos contribuyeron a la formación de un panorama de la toponimia regional del Perú, existen otros estudios que han generado polémica. Un ejemplo de ellos es el de Soto (1976), donde se concluye que el quechua de Cajamarca es cañarense Para dar con esta conclusión, el autor abordó los aspectos fonológicos y morfológicos de dicha variante. No obstante, Burgos (2003) afirmó que la lengua cañari se desarrolló principalmente en territorio de lo que hoy es Ecuador, y es que, en efecto, el quechua de Cajamarca contiene algunas raíces del mochica y del culle. Por otro lado, Espinoza (1973) señaló que no es acertado en cuanto a los significados de los topónimos. Este autor, por su parte, ha realizado estudios generales y dispersos, por lo que sus interpretaciones son parciales, sobre todo al relacionar el quechua norteño únicamente con la variedad del Cusco.

\section{Metodología}

Este trabajo es de carácter cualitativo y su diseño es de tipo no experimental con un nivel exploratorio descriptivo. Como unidades de estudio se tomaron en cuenta el aspecto morfológico y semántico de los topónimos de la provincia de Huarochirí. El estudio se realizó entre 2015 y 2017. La investigación se basa en la teoría estructuralista de Pottier (1945). Inicialmente, se realizó un trabajo de campo en el que se entrevistó a los pobladores con previa coordinación del lugar, la hora y la fecha. Al respecto, cabe aclarar que En la mayoría de las entrevistas se reiteró esa información para la confirmación de los datos. Después, se realizó el trabajo de gabinete, donde se analizaron la forma y el contenido de los topónimos, que a su vez fueron clasificados según su origen etimológico, bien fuese quechua, aimara, jacaru o español, así como su contenido semántico, relacionándolos en su significado con la fitonimia, zoonimia, hidronimia, entre otras.

En principio, se definió como técnica de investigación la realización de entrevistas abiertas y reiteradas. Para la realización de las mismas, se hizo previa coordinación con los pobladores del lugar, la hora y la fecha más propicio para los participantes. Teniendo en cuenta esto, se decidió diseñar un cuestionario como instrumento de recolección de datos, el cual contenía 30 preguntas sobre 12 temas, además de las preguntas abiertas que se anotaban en las fichas. Los cuestionarios se aplicaron durante las horas de la comida o en los descansos, así como durante las horas de trabajo en las actividades agrícolas y en la celebración de las fiestas tradicionales. Las preguntas realizadas se refirieron a los diferentes lugares que se indicaron, según los espacios donde se ejecutó el diálogo. Para ello, se seleccionaron a personas mayores de cuarenta años, residentes del lugar, y dedicadas a la agricultura y a la ganadería de consumo familiar. Entre las características de las personas entrevistadas, destaca su actitud abierta y comunicativa. 
La estructura morfológica y el contenido semántico de los topónimos de la provincia de Huarochirí (Perú)

Así, pues, el proceso de investigación se organizó de la siguiente manera. Primero, se realizó una revisión exhaustiva de la literatura referente al tema. Asimismo, se recogió información de documentos oficiales como la Carta Nacional, levantada por el Instituto Geográfico Nacional (1989), así como de varios documentos oficiales de los lugares de estudio. A continuación, se elaboró el corpus lingüístico de 140 topónimos.

En el cuadro 1 se muestran los 140 topónimos que fueron objeto de estudio en los niveles morfológico y semántico, todos ellos correspondientes a la provincia de Huarochirí.

\begin{tabular}{|c|c|c|c|}
\hline Acobamba & Alloca & Anchucaya & Antakallo \\
\hline Antapucho & Antapucro & Arampampa & Autisha \\
\hline Ayas & Boquicuesta & Callahuanca & Canchacalla \\
\hline Canchaje & Canchanya & Canta Huaycho & Carachacra \\
\hline Carampoma & Carcashiqui & Carhuavilca & Casapalca \\
\hline Cocachacra & Cochahuayco & Colpayunco & Comalipa \\
\hline Condorcoto & Condorsuni & Corcona & Cucuya \\
\hline Cumbe & Challape & Chaclla & Chapo \\
\hline Chauca & Chaupimarca & Chaymalla & Chiacancha \\
\hline Chilca & Chingana & Chiwacoto & Chucumayo \\
\hline Chucuncuya & Chuya & Escomarca & Huacapune \\
\hline Huacrahualla & Huachupampa & Hualapunco & Huanano \\
\hline Huancata & Huancayre & Huanza & Huaquicha \\
\hline Huarahuara & Huarango & Huarichaca & Huariquiña \\
\hline Huarochirí & Huayanche & Huayre & Koto Gentile \\
\hline Lahuaytambo & Langa & Laraos & Lahuaytambo \\
\hline Laya & Linday & Lúcumo & Lurín \\
\hline Llacallaca & Llacsatambo & Llaquistambo & Mala \\
\hline Marcamarca & Marcahuasi & Mariatana & Matakaka \\
\hline Matucana & Orcocoto & Otao & Pampilla \\
\hline Palakala & Pariakaka & Pascanita & Pecagasha \\
\hline Peña Culebra & Peña Llorana & Pongo & Pullocanchi \\
\hline Purunhuasi & Quilcamachay & Quilquichaca & Quinti \\
\hline Quirihuay & Quiripa & Ricardo Palma & Rímac \\
\hline $\begin{array}{c}\text { San Andrés de } \\
\text { Tupicocha }\end{array}$ & $\begin{array}{l}\text { San Antonio de } \\
\text { Chaclla }\end{array}$ & $\begin{array}{c}\text { San Bartolomé — antes } \\
\text { Suquiarcancha- }\end{array}$ & $\begin{array}{l}\text { Santa Cruz de } \\
\text { Cocachacra -antes } \\
\text { Macipa- }\end{array}$ \\
\hline Santa Cruz de Ucros & $\begin{array}{c}\text { Santa Eulalia -antes } \\
\text { Olalla, Acopaya- }\end{array}$ & San Damián & $\begin{array}{c}\text { Santo Domingo de los } \\
\text { Olleros }\end{array}$ \\
\hline $\begin{array}{c}\text { San Jerónimo de Surco } \\
\text { —antes Picoy- }\end{array}$ & San Juan de Matucana & \begin{tabular}{|ccc} 
San & Juan & de \\
& Tantaranche & \\
\end{tabular} & San José de Tucre \\
\hline
\end{tabular}


La estructura morfológica y el contenido semántico de los topónimos de la provincia de Huarochirí (Perú)

\begin{tabular}{|cc|c|c|c|}
\hline $\begin{array}{c}\text { San } \\
\text { Mapicara }\end{array}$ & $\begin{array}{c}\text { San Lázaro de } \\
\text { Escomarca }\end{array}$ & $\begin{array}{c}\text { Santa María de Jesús } \\
\text { de Huarochirí }\end{array}$ & $\begin{array}{c}\text { San Mateo de } \\
\text { Huanchor }\end{array}$ \\
\hline San Mateo de Otao & San Pablo de Chauca & $\begin{array}{c}\text { San Pedro de } \\
\text { Chiacancha }\end{array}$ & San Pedro de Casta \\
\hline $\begin{array}{c}\text { Pedro de } \\
\text { Huancayre }\end{array}$ & $\begin{array}{c}\text { Santo Toribio de } \\
\text { Cumbe }\end{array}$ & Santiago de Tuna & Sangallaya \\
\hline Siquirachi & Sisicaya & Songos & Sumacpacha \\
\hline Suquiarcancha & Surco & Tamboraque & Tantaranche \\
\hline Tapicara & Ticapampa & Tucre & Tumbapaccha \\
\hline Tumna & Tupicocha & Tutayquiri & Ucros \\
\hline Vicas & Yacumayque & Yanamenco & Yanamanqui \\
\hline Yananeque & Yanascocha & & \\
\hline
\end{tabular}

Tabla 1. Corpus toponímico perteneciente a la provincia de Huarochirí, Perú.

\section{Resultados y discusión}

Los resultados se dividen según las unidades de estudio. Por ello, en primer lugar, se presentarán las características morfológicas de los topónimos de la provincia de Huarochirí, teniendo en cuenta el aspecto sincrónico de la lengua, como lo plantearon Saussure (2005), Sapir (1966) y Pottier (1969). Este último recogió en sus tratados lingüísticos las características de las lenguas originarias de América.

En el presente estudio de los topónimos se encuentran características lingüísticas importantes, como el predominio de las lexías simples y compuestas planteado por Pottier (1969), que tienen mayor cantidad que los lexemas simples. Asimismo, se observa la aplicación de sufijos propios de las lenguas aimara y quechua, para cumplir funciones sintácticas en frases y oraciones. Se reconoce al morfema raíz como equivalente a lexema, el cual contiene el significado básico que tiene en la lengua a la que pertenece. Los sufijos, un tipo de morfemas ligados a una raíz, expresan la categoría de la palabra y relaciones con otras palabras, según las lenguas en que se presentan (Solís, 1997; Chávez, 2003; Cerrón-Palomino y Chacón, 1976; Baldoceda, 1993; Hardman, 1973; Belleza, 1995). A continuación, se presenta la caracterización morfológico-sintáctica de un grupo de casos analizados.

\subsection{Rasgos morfológicos de los topónimos de la provincia de Huarochirí}

a) Algunos topónimos están formados por dos lexemas de la misma lengua con categoría de sustantivos, donde el primero es modificador y, el segundo, modificado. Ejemplo: Antacallo, de anta, «cobre»—lex. Q, sustantivo-, y qallu, «lengua» - lex. Q, sustantivo-: Lexía = Lex Q + Lex Q.

b) Existen topónimos formados por dos lexemas, uno de origen quechua y otro aimara, ambos de diferentes 
La estructura morfológica y el contenido semántico de los topónimos de la provincia de Huarochirí (Perú) categorías: adjetivo y sustantivo. Lexía = Lex Q + Lex Ai. Ejemplo: Chaupimarca de chawpi, «centro» - lex Q. adj.-, y marka, «pueblo» - lex. Ai. Sustantivo—, que juntos significan «pueblo del centro». Ambos lexemas con categoría de sustantivos, Lexía = Lex. Q + Lex Ai. Es importante aclarar que marka es «pueblo», «ciudad», o «región» en aimara, mientras que en variedades sureñas de quechua y otras la palabra es llaqta — pero en las hablas de Áncash y Junín, dicen marka y malka, respectivamente-

c) Algunos están constituidos por un solo lexema, en este caso cumpliendo función de sustantivo, adjetivo, verbo o adverbio — ver figura 1 —. Por ejemplo, con la palabra quechua Allauca de allawqa, «derecha» —adv. —.

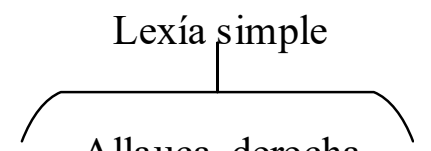

Allauca, derecha

Figura 1. Constitución de la lexía Allauca

d) Se puede observar también la inserción de una sílaba dentro de un lexema. Por ejemplo, la primera sílaba de chunculla, que es $<$ chun $>$, pasa a ser $<$ chucun $>$, y de allí se obtiene chucuncuya por adición de /ku/. La chunculla era un objeto ritual de oro que Pariacaca dio a los yauyos advenedizos para que mejoraran su estatus, según el relato del capítulo 24 de la obra de Taylor (1610/1999).

e) Las lexías que presentan dos o más lexemas enuncian un solo significado, como se aprecia en el topónimo Matacaca (ver Figura 2).

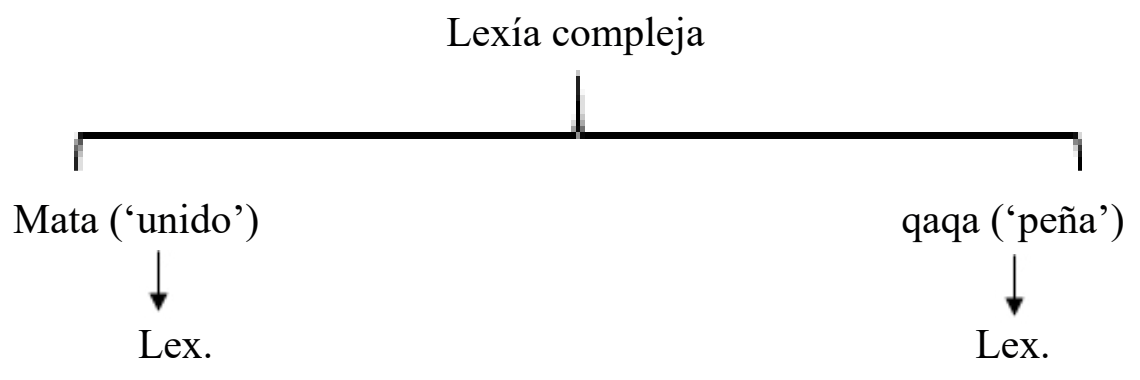

Figura 2. Constitución de la lexía quechua Matacaca

Nota. Nótese «Peña pegada [a otra]». La información de mata «pegado», «unido» se ha obtenido de T. Laime (2007, p. 66).

d) También puede presentarse un topónimo constituido por un lexema del español y otro de lengua nativa, lo que produce un topónimo híbrido (ver Figura 3). 


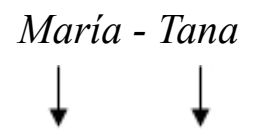

español quechua

Figura 3. Constitución de la lexía Mariatana

Mariatana es un topónimo formado por María, nombre español, y taana, «asiento», que en su conjunto significan «Cerro María». La palabra taana corresponde al quechua norteño - Áncash—, que tuvo influencia en la sierra de Lima. Con el tiempo, la vocal larga de taana cambió a vocal corta y ahora se tiene simplemente tana. Baldoceda (1993) menciona topónimos que contienen tana, como Mariatana y Chucutana. En varios lugares del Perú existe el topónimo Condortiana — < kuntur tiyana - como nombre de cerros o cumbres de cerros; y en Áncash Condortaana es el equivalente de Condortiana, porque usan la raíz taa- para expresar la idea de sentarse, mientras que en el sur dicha raíz es tiya-. En cuanto al significado, de designar un asiento o lugar de asiento, taana llegó a significar «cerro» por metonimia.

Otro topónimo mixto se presente, San Juan de Tantaranche, cuyo componente no español es hasta el momento parcialmente desconocido. La primera parte del nombre, San Juan de, tiene san, apócope de santo, el nombre propio Juan, de origen español, y la preposición $d e$. En la parte nativa, <tantaranche>, se intentó segmentar en dos partes: t'anta, «pan», o tanta, «reunión», que corresponden al aimara o al quechua, y <ranche>, elemento que no se ha podido identificar en diccionarios del quechua, aimara o jacaru.

g) Asimismo, algunos topónimos de origen español han reemplazado al nombre original, que era jacaru o quechua. Un ejemplo es San Bartolomé, antiguamente Suquiarcancha o Soquiarcancha, del jacaru shuq'u, «absorber» (Belleza, 1995), sufijo causativo -ya, sufijo de cantidad -ra $\longrightarrow$ shuq'yara- más Q. kancha, «terreno cercado», que quiere decir «terreno cercado con sumidero», Otro ejemplo es Santa Cruz, antes Cocachacra o Macipa.

h) Se da el caso de un topónimo de origen español en forma de lexía (ver Figura 4).

Por ejemplo: boca + cuesta $=$ boquicuesta

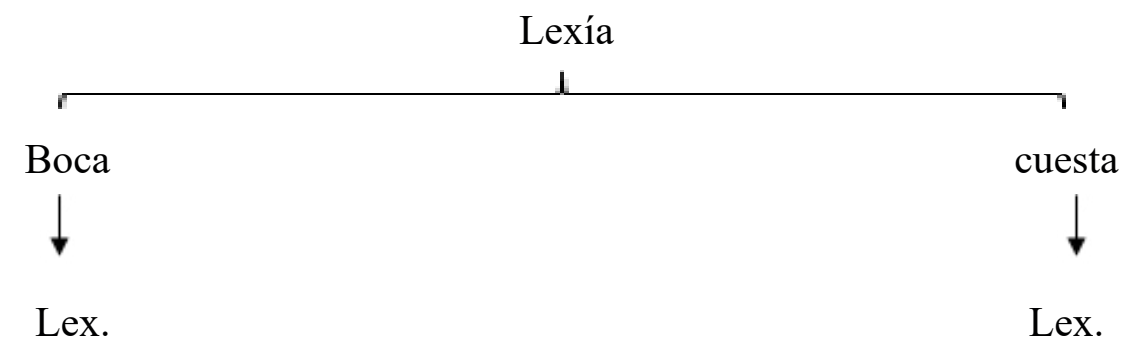

Figura 4. Topónimo de origen español 
La estructura morfológica y el contenido semántico de los topónimos de la provincia de Huarochirí (Perú)

\subsection{Características semánticas de los topónimos de la provincia de Huarochirí}

En el análisis semántico se tomó como referencia la teoría formal y conceptual de Saussure (2005). Estos resultados coinciden con los trabajos de Solís (1997), Chávez (2003), Mejía (2007), Amaro et al. (2014) y Baldoceda (1993). A continuación, se presentan algunos casos extraídos del corpus.

a) Por situaciones religiosas o políticas, en la zona de Huarochirí algunos topónimos en lengua nativa fueron modificados añadiéndoles componentes del español. En gran medida, se trata de nombres de santos cristianos, lo que se puede comprobar en documentos antiguos como los de Ávila (1910), los cuales se remontan a la época colonial. Por ejemplo, San Mateo de Huánchor, San Lorenzo de Quinti, San Mateo de Otao, San Juan de Matucana, Santiago de Tuna, Santa Cruz de Cocachacra, San Miguel de Tapicara, entre otros. Ocurre también que hay topónimos con todos sus elementos del español, como San Jerónimo de Surco y Santo Domingo de los Olleros.

b) En efecto, algunos topónimos con nombres de santos cristianos también han reemplazado el nombre originario americano, lo cual es consecuencia de la campaña de extirpación de lo que los invasores consideraban idolatrías en la zona de Huarochirí, tal y como lo señala Ávila (1962). Era ya una nueva realidad que mostraba la superposición de lo occidental a lo nativo, en una coexistencia cultural e ideológica impuesta y que la población ha llegado a asimilar, no sin conservar elementos propios, claro ejemplo de sincretismo.

c) También se tienen topónimos de origen quechua que hacen referencia a nombres de divinidades andinas de Huarochirí. Por ejemplo:

\subsubsection{Pariacaca. Lexía Q.}

En el análisis de este topónimo hay que dar cuenta de dos componentes, representados ortográficamente como $<$ paria $>$ y $<$ caca $>$. Para explicar el primero debe tenerse en cuenta que siendo el Pariacaca un nevado, no es apropiado intentar explicar <paria $>$ — /pariya/ o /parya/_ con la raíz pari, «caliente» — que, además, no explica la /a/ - sino con pariya o parya, «cinabrio». En cuanto al segundo <caca>, es qaqa «peña», «roca», «precipicio», lo que da el significado «peña del cinabrio». Pariacaca es un gran cerro rocoso y nevado, que lleva el nombre de un dios mítico de la sierra de Lima, del cual el Manuscrito quechua de Huarochirí da amplia información (Taylor, 1610/1999). La presencia de pariya en la composición del nombre se explica porque el cinabrio era usado como ofrenda a las huacas y a los dioses. Al respecto, Arriaga (1564-1622/1920) afirmó lo siguiente: «Paria es polvos de color colorado como de vermellón que traen de las minas de Huancavelica, que es el metal de que se saca el azogue, aunque más parece açarcón» (p. 47).

Los significados dados se presentan a continuación: 1. Su significado alude a las ofrendas con cinabrio que hacían los fieles a este cerro que era considerado un apu o protector. Se considera que no es pertinente explicar este nombre con pari, «caliente», pues el área es fría por la altura, y además el Pariacaca es un nevado. Se 
La estructura morfológica y el contenido semántico de los topónimos de la provincia de Huarochirí (Perú) descartó también paria, «gorrión» (Gonçález, 1604/1989), por no adecuarse a la evocación mágico-religiosa del nombre. 2. Lugar ubicado a 5750 m s.n.m., en los Andes centrales, entre los departamentos de Lima — parte alta de Huarochirí- y Junín. 3. El lugar tiene dos picos, el pico norte a 5730 m s.n. m., y el pico sur a 5750). 4. El nombre hace referencia al dios principal de Huarochirí y Yauyos, identificado con un nevado del mismo nombre, conocido también como Yaru, la divinidad de los llacuaces. Pariacaca, según la mitología local de Huarochirí, es el hijo de Cuniraya, deidad que fue adorada en los Andes del sur de ese lugar (Cerrón-Palomino, 2015a).

\subsubsection{Tutayquiri. Lexía Q. Ai.}

Proviene del Q. tuta, «noche», sufijo -ya verbalizador transformativo y Ai. Ikiri, «el que duerme» $<<i k i$ «dormir» + -ri agentivo o que realiza la acción del verbo-, con lo que se obtiene tuta + -ya $+i k i r i$, donde tuta + -ya complementa a ikiri; y esta formación tutayaikiri experimenta una pérdida fonética que produce tutaykiri <Tutayquiri>, así como en aimara colonial, de kimsa, «tres» resulta <quimçairi> —/kimsayri/— (Torres, 15161529). Es importante señalar que a ikiri se le asigna étimo aimara, pero, por la cercanía geográfica de Yauyos, podría ser una palabra jacaru, lengua en que «durmiente» es exactamente igual que en aimara: ikiri. En todas las variedades del quechua, el sufijo transformativo - ya se une a raíces nominales como tuta para constituir una nueva raíz verbal. Cusihuamán (1976/2001) da un ejemplo, precisamente, con tuta-ya-y, «anochecer», «oscurecer», «eclipsar».

Los significados posibles se presentan a continuación: 1. Su significado sería «el que duerme haciendo que anochezca». 2. El lugar es una zona accidentada. Asimismo, según la leyenda, Tutayquiri nace en el cerro Huarascacha, al noroeste de San Damián. 3. El lugar geográfico es accidentado y por él pasa un camino que cubre varios pueblos de Huarochirí, denominado La Ruta de Tutayquiri (Cerrón-Palomino, 2015a). 4. El nombre alude al dios Tutayquiri, del periodo Horizonte Medio, quinto hijo de Pariacaca que tiene en su poder las tierras Allauca, Pitocaya, Tagana, Pacota, Tupicocha, Tumna - Tuna —, Chauti —Chaute —, Quebrada de Carnacha y Suquiarcancha — San Bartolomé- (Bueno, 1992).

a) Existen algunos topónimos en lengua nativa. Por ejemplo:

Langa, de origen quechua: llanka que es «greda», «barro». De la forma original /llamka/ $(<1 \mathrm{lamca}>)$, que aparece en Santo Tomás (1570/1995), hubo cambio a lamka, por despalatización de /11/. La secuencia de cambios fue la siguiente: despalatización llamka > lamka, labialización de /n/lamka > lanka, sonorización lanka >langa.

Yayama, del Q. yaya, «padre» y Ai. ma «agua», que significa «agua del padre». A partir del hecho de que en aimara y jacaru los pronombres personales tienen en caso nominativo una forma con dos sílabas, y en posesivo y acusativo con una sílaba — como jacaru juma, «tú», markma, «tu pueblo», upa, «él», markpha, «su pueblo» (Belleza, 1995) — se postula la raíz monosilábica $m a$, similar a uma, «agua», en aimara y jacaru, que está presente, por ejemplo, en el topónimo Yanama - «agua negra», «agua turbia»—, que existe en varias partes del Perú.

Yanacocha, del Q. yana, «negro» y qucha, «lago», «laguna», «estanque», por lo que Yanacocha significa 
La estructura morfológica y el contenido semántico de los topónimos de la provincia de Huarochirí (Perú) «lago negro», «laguna negra».

Pongo, deriva de punku, «puerta»; y es palabra compartida por el quechua y el aimara.

Lahuaytambo, que está formado por dos palabras del quechua: el sustantivo lawa, «sopa de harina muy suelta», el sufijo -y que une raíces — por ejemplo, de tiqu, «apretado», sale tiquytiquy, «muy ajustado» (Gutiérrez et al., 2007) - y tampu, «posada», «establecimiento en el que los viajeros descansan y se alimentan». También tenemos el Vocabulario de Neli Belleza (1955), que inicia la letra Y con el sufijo interradical -y-, el cual sirve para unir raíces nominales, lo que ejemplifica utilizando qala, «piedra», que da qalayqala «redondo — como piedras— - . Se debe señalar que tampu es una palabra compartida por el quechua y el aimara.

b) El corpus toponímico también muestra algunos nombres de origen español. Ejemplos: Ricardo Palma, Boquicuesta, Peña Culebra, y nombres de santos cristianos que fueron tomados por imposición durante la evangelización y la extirpación de idolatrías (Arriaga, 1564-1622/1920).

c) Los actuales pobladores de la provincia de Huarochirí desconocen las raíces de su cultura, motivo por el cual no sienten identificación con su historia y desconocen las lenguas originarias que se encuentran en los contenidos semánticos de los topónimos.

d) Para la recaudación de datos, al consultar sobre el significado de los nombres de los lugares, relataron, en la mayoría de los casos, las características geográficas del lugar a la que nomina el topónimo.

e) Existe reduplicación de lexemas, empleada para enfatizar el significado del signo. Por ejemplo:

Marcamarca y Llacallaca, que son topónimos de origen quechua. El primero, markamarka, significaría «casas con altos» — para <marca> se registra el significado «el soberano, o los altos de la casa» (Gonçález, 1604/1989) — . Si se postulara aimara el significado sería «pueblo pueblo», o sea «varios o muchos pueblos». El segundo, llaqallaqa, quiere decir «hoja verde de maíz», que posiblemente alude a sembríos de maíz. El dato de llaqa viene del diccionario quechua de Laime (2007). Se ha buscado un lexema apropiado para el contexto, y no se ha tomado en cuenta, por ejemplo, <Llaca>, que está en Bertonio (1612) con el significado «plumas delgadas que ay en las alas del Buytre y otros paxaros»».

Se entiende que esta repetición o reduplicación en Marcamarca y Llacallaca expresa intensidad o multiplicidad. En quechua, por ejemplo, se tiene piña, «enojado/a»; piñaypiña, «enojadísimo/a». En jacaru, de pata, «andén», deriva, con caída de una vocal, patpata, «andenes», «andenería».

Finalmente, en el corpus onomástico de la provincia de Huarochirí se manifiestan diferentes clases de topónimos: antrotopónimos, hagiotopónimos, hidrotopónimos, geomorfotopónimos, topónimos de orientación y situación geográfica, topónimos de materiales, domotopónimos, agrotopónimos, fitotopónimos, zootopónimos, arqueotopónimos, entre otros. (Chávez, 2019). 
La estructura morfológica y el contenido semántico de los topónimos de la provincia de Huarochirí (Perú)

\section{Conclusión}

El estudio de la toponimia en la provincia de Huarochirí evidencia la existencia de su pasado, sobre todo si se refiere al lugar donde se ubicaron las comunidades andinas que sucesivamente hablaron la lengua aimara — del Collao — el jacaru o cauqui — de estrecho parentesco con el aimara —, la lengua quechua y, finalmente, la lengua española.

Se nota la existencia de procesos fonológicos, tales como apócope y síncopa, y aglutinación de lexemas que derivan en lexías simples y compuestas, evidenciando un contenido semántico unitario que se desprende de y refleja de manera natural el ethos cultural de dicho espacio geográfico. Los topónimos, desde el punto de vista lingüístico, están estructurados sobre la base de lexemas y lexías, donde se puede observar la aglutinación de los elementos lingüísticos, el espíritu integrador del hombre y la naturaleza, y la visión directa y cósmica expresados en formas orales sintéticas.

Como se ha mostrado, la toponimia quechua de Huarochirí sobrevive algo alterada por la lengua y la escritura castellanas, lo que es manifestación de la introducción de palabras de origen español, con su respectiva carga semántica y cultural. También se encuentran topónimos con elementos del jacaru o del aimara, como Soquiarcancha y Yayama. No obstante, la mayor cantidad de los nombres son de origen quechua.

Otro aspecto importante es que existen topónimos que se relacionan con los entes culturales, un hecho que permite conocer más a fondo la cosmovisión del hombre andino de esa época, así como sus concepciones religiosas, económicas y sociales. Todo ello puede comprobarse en las entidades culturales, como caminos —odónimos—; arquitectónicos como edificios; y agrónomos como chacras, reservorios, puentes, calles, circunscripciones políticas, entre otros.

En cuanto al análisis, se advierte que en la toponimia de Huarochirí existen sufijos y lexemas cuyo significado o filiación lingüística aún no se ha podido encontrar — como es el caso de < ranche $>$ en San Juan de Tantarancheporque la lengua a la que pertenecen ha desaparecido o porque, siendo de lengua conocida, eran en su tiempo de poco uso o se hicieron obsoletos; o, bien, correspondían a culturas mucho más antiguas que estuvieron en esos espacios geográficos y que apenas dejaron alguna huella. 
La estructura morfológica y el contenido semántico de los topónimos de la provincia de Huarochirí (Perú) Referencias bibliográficas

1. Amaro, Z., Cruz, E. y Huanaco, E. (2014). La toponimia del distrito de Huaccana, provincia de Chincheros, departamento de Apurímac (Tesis de licenciatura). Universidad Nacional Mayor de San Marcos. http://repositorio. une.edu.pe/bitstream/handle/UNE/698/T025_03328434_T.pdf?sequence=1\&isAllowed=y

2. De Arriaga, P. (1564-1622/1920). La extirpación de la idolatría en el Perú. Lima: Imprenta y Librería Sanmartí y Ca.

3. Ávila, F. (1962). Dioses y hombres de Huarochirí. Narración bilingüe recogida por Francisco de Ávila (¿1598?). Lima: Instituto de Estudios Peruanos.

4. Ávila, J. (1910). Carta del padre Ávila y Juan de Cuevas. En J. Arriaga La extirpación de la idolatría en el Perú (pp. 180-264). España: Ediciones San Martín.

5. Baldoceda, A. (1993). Topónimos de Canta. Lima: Fondo Editorial de la Universidad Nacional Mayor de San Marcos.

6. Belleza, N. (1995). Vocabulario Jacaru-Castellano Castellano-Jacaru. Cuzco: Centro de Estudios Regionales Andinos Bartolomé de Las Casas.

7. Bertonio, L. (1612). Vocabvlario de la Lengva Aymara. Juli, Francisco del Canto (editor). https://www.wdl.org/ es/item/13776/

8. Bueno, A. (1992). Arqueología de Huarochirí. En Huarochirí ocho mil años de historia. Tomo vi. Edición de la Municipalidad de Santa Eulalia de Acopaya. (pp. 13-62). Lima: DESA.

9. Burgos, H. (2003). La identidad del pueblo cañari. De-construcción de una nación étnica. Quito: Ediciones Abya-Yala.

10. Cerrón-Palomimo, R. (2015a). El puquina como lengua de Tiahuanaco y de los incas primordiales. 20 diapositivas en PowerPoint. Lima: PUCP-Radio Onda Azul (Puno).

11. Cerrón-Palomino, R. (2015b). Toponimia andina. Problemas y métodos. Lexis, 39(1), 183-197.

12. Cerrón-Palomino, R. \& Chacón, J. (1976). Diccionario quechua Junin-Huanca. Lima: Ministerio de Educación. 13. Chávez, A. (2003). La toponimia en la zona andina de Ancash. Con especial referencia sobre el topónimo shiqui. Lima: Editorial de la Universidad Nacional Mayor de San Marcos.

14. Chávez, D. (2019). Estudio morfológico y semántico de los topónimos de la Provincia de Huarochirí (Tesis de Maestría).UniversidadEnriqueGuzmányValle.http://repositorio.une.edu.pe/bitstream/handle/UNE/3096/TM\%20 CE-Le\%204433\%20C1\%20-\%20Chavez\%20Bellido\%20Dina\%20Emeteria.pdf?sequence=1\&isAllowed=y

15. Cuba, M. (2018). Lenguas en contacto en la toponimia de la Sierra Norte del Perú. En R. Risco (Coord.), Estudios de variación y contacto lingüístico en el español peruano (pp. 18-80). La Plata: Universidad Nacional de La Plata. Facultad de Humanidades y Ciencias de la Educación.

16. Cusihuamán, A. (1973). Diccionario quechua Cuzco-Collao. Lima: Ministerio de Educación.

17. Cusihuamán, A. (1976/2001). Gramática Quechua Cuzco-Collao (2. ${ }^{a}$ edición). Cuzco: Centro de Estudios 
La estructura morfológica y el contenido semántico de los topónimos de la provincia de Huarochirí (Perú) Regionales Andinos Bartolomé de Las Casas.

18. Durand, J. (1921). Etimologías perú- bolivianas. La Paz: Textos gráficos de La Prensa.

19. Espinoza, M. (1973). Topónimos quechua del Perú. Lima: Comercial Santa Elena, Cosesa.

20. Fernández, A. (2001). La variación actancial en Ranquel (Mapuche). Buenos Aires: CONICET, Universidad de Buenos Aires.

21. Fernández, A. (Ed.). (2002). Testimonio de los últimos ranqueles. Buenos Aires: Editorial de la Facultad de Filosofía y Letras Universidad de Buenos Aires.

22. Frago, J. (1991). Problemas, métodos y enseñanzas de la toponimia. En V. Gasteiz (Ed.), Actas de las I Jornadas de Onomástica, Toponimia, abril de 1986. (pp. 201-220). Bilbao: Euskaltzaindia.

23. Gonçález, D. (1604/1989). Vocabvlario de la Lengva General de todo el Perv. Francisco del Canto (editor). http:/www.letras.ufmg.br/padrao_cms/documentos/profs/romulo/VocabvlarioQqichuaDeHolguin1607.pdf

24. Gutiérrez, L., Mantilla, L. \& Huamán, S. (2007). Diccionario de Quechua Apurimeño (Versión Preliminar). https://es.slideshare.net/waqanky/dic-apurimac-quechua

25. Hardman, M. (1973). Jaqaru/Compendio de Estructura Fonológica y Morfológica. La Paz: Instituto de Estudios Peruanos e Instituto Indigenista Interamericano.

26. Instituto Geográfico Nacional. (1989). Atlas del Perú. Lima: Instituto Geográfico Nacional.

27. Laime, T. (2007). Diccionario bilingüe Iskay simipi yuyayk'ancha Quechua-Castellano Castellano-Quechua. https://futatraw.ourproject.org/descargas/DicQuechuaBolivia.pdf

28. Mejía, E. (2007). Toponimia del distrito de Yaután (Tesis de licenciatura). Universidad Nacional Mayor de San Marcos. https://cybertesis.unmsm.edu.pe/bitstream/handle/20.500.12672/946/Mej\%c3\%ada_ mr.pdf? sequence $=1 \&$ isAllowed $=\mathrm{y}$

29. Mollo, R \& Vera, D. (2017). Toponimia indígena del sur de San Luis. http://norbertomollo.blogspot.pe/2017/07/ toponimia-indigena.html

30. Parker, G. (1975). Diccionario polilectal del quechua de Ancash. Lima: Fondo Editorial de la Universidad Nacional Mayor de San Marcos.

31. Pottier, B. (1969). Gramática del español. Barcelona: Gredos

32. Rodríguez, A., Rodríguez, I. \& Vázquez, A. (2017). Métodos y técnicas de análisis toponímico urbano y su aplicación en la ciudad de Toledo. Boletín de la Asociación de Geógrafos Españoles, 75, 101-126.

33. Rostworowski, M. (1978). Señoríos indígenas de Lima y Canta. Lima: Instituto de Estudios Peruanos.

34. Santo Tomás, D. (1570/1995). Arte y Vocabvlario en la Lengua General del Perv, llamada Quichua, y en la lengva española. Francisco del Canto (impresor). https://www.wdl.org/es/item/13773/

35. Sapir, E. (1966). El lenguaje. Introducción al estudio del habla. México: Fondo de Cultura Económica.

36. Saussure, F. (2005). Curso de lingüistica general. Buenos Aires: Editorial Losada.

37. Solís, G. (1997). La gente pasa, los nombres quedan. Introducción en la toponimia. Lima: Ediciones Lengua y Sociedad. 
La estructura morfológica y el contenido semántico de los topónimos de la provincia de Huarochirí (Perú) 38. Soto, C. (1976). Gramática quechua Ayacucho-Chanca. Lima: Ministerio de Educación.

39. Taylor, G. (1610/1999). Ritos y tradiciones de Huarochirí (2. ${ }^{a}$ edición). Lima: Instituto de Estudios Peruanos, Instituto Francés de Estudios Andinos, Banco Central de Reserva y Universidad Particular Ricardo Palma.

40. Torres, V. (2007). Lurinyauyo: pervivencia histórica de Huarochirí para la identidad regional y la conciencia nacional (propuesta educativa para el área de Ciencias Sociales) (Tesis de maestría). Universidad Nacional de Educación Enrique Guzmán y Valle. http://repositorio.une.edu.pe/handle/UNE/345

41. De Torres Rubio, D. (1616). Arte de la Lengva Aymara. Lima: Imprenta de Francisco del Canto.

42. Trapero, M. \& Santana, E. (2016). Toponimia de las Islas Canarias. https://www.ulpgc.es/noticia/presentaciondel-nuevo-portal-toponimia-islas-canarias 
Anexo 1: Mapa físico político de la provincia de Huarochirí

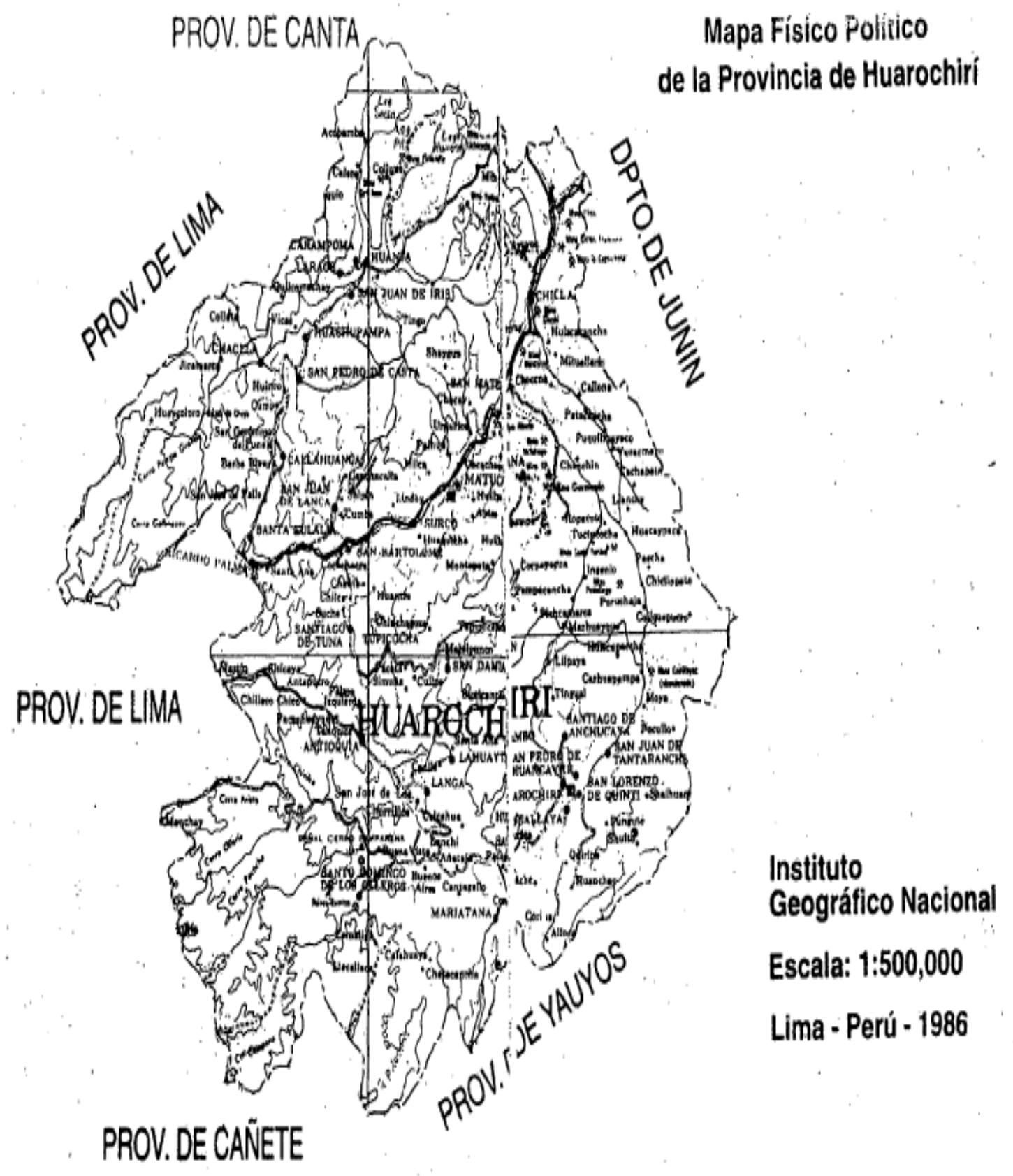

Nota: Tomado de V. Torres (2007, p. 50). 